\title{
Erythropoietin Decreases Cytotoxicity and Nitric Oxide Formation Induced by Inflammatory Stimuli in Rat Oligodendrocytes
}

\author{
K. GENC ${ }^{1}$, S. GENC ${ }^{1}$, H. BASKIN ${ }^{2}$, I. SEMIN ${ }^{3}$ \\ ${ }^{1}$ Learning Resources Center Research Laboratory, ${ }^{2}$ Department of Microbiology, ${ }^{3}$ Department of \\ Physiology, School of Medicine, Dokuz Eylul University, Izmir, Turkey
}

Received January 5, 2005

Accepted March 23, 2005

On-line available April 26, 2005

\begin{abstract}
Summary
In the present study, we investigated whether erythropoietin (Epo) has a protective effect against cytotoxicity induced by interferon-gamma (IFN- $\gamma$ ) and lipopolysaccharide (LPS) in primary rat oligodendrocyte cultures. The possible modulatory effect of erythropoietin on inducible nitric oxide synthase (iNOS) mRNA expression and nitrite production were also analyzed. Erythropoietin exerted a significant protective effect against IFN- $\gamma$ and LPS-induced oligodendrocyte injury as determined by lactate dehydrogenase assay. Treatment with erythropoietin inhibited the expression of iNOS mRNA and nitrite production resulting from proinflammatory stimulation by IFN- $\gamma$ and LPS. These results suggest that erythropoietin has protective effects against inflammatory oligodendrocyte injury in vitro and may play a protective role in neurological disorders characterized by oligodendrocyte death, such as multiple sclerosis.
\end{abstract}

\section{Key words}

Erythropoietin $\bullet$ Oligodendrocyte $\bullet$ Cytotoxicity $\bullet$ Lipopolysaccharide $\bullet$ Interferon-gamma $\bullet$ Nitric oxide

\section{Introduction}

Erythropoietin (Epo) is a hematopoietic cytokine and growth factor that stimulates erythropoiesis (Genc et al. 2004). Recently, the presence of Epo and its receptor (EpoR) in the central nervous system (CNS) and neuronal cells has been verified. Many in vitro and in vivo studies have demonstrated that Epo has neuroprotective effects against various insults such as hypoxia, ischemia, trauma, and inflammation (for review see Maiese et al. 2004, Genc et al. 2004). However, the primary pathology in some acquired disorders of CNS with different etiologies (inflammatory, toxic, autoimmune, etc.) concerns myelin injury and oligodendrocyte death (Benn et al. 2001). Additionally, in acute and chronic neurodegenerative disorders of the CNS such as stroke, hypoxic-ischemic and traumatic injury, white matter involvement, myelin loss and oligodendrocyte death also occur with axonal and neuronal injury (Benn et al. 2001). Therefore, the determination of the agents that may prevent oligodendroglial death in various injury models in vitro might contribute to establish effective treatment strategies for these neurological diseases. Erythropoietin might be one of these candidate agents. 
Various events such as inflammatory processes, glutamate excitotoxicity, the formation of reactive oxygen and nitrogen species, and apoptotic cell death might be involved in the pathogenesis of oligodendrocyte death in CNS diseases (Benn et al. 2001). Since Epo exerts its neuroprotective effect via action on these mechanisms (Maiese et al. 2004, Genc et al. 2004), it is likely that it also has oligodendroglioprotective action. Recently, it has also been shown that rat oligodendrocytes express EpoR, and Epo promotes the maturation of oligodendrocytes (Sugawa et al. 2002). Epo prevents secondary oligodendrocyte death due to trauma in spinal cord white matter in vivo (Gorio et al. 2002).

In the present study, we aimed to investigate the possible protective effect of Epo against lipopolysaccharide (LPS) and interferon-gamma (IFN $\gamma$ )-induced inflammatory cytotoxicity in neonatal rat oligodendrocyte cultures. The possible modulatory effect of Epo on inducible nitric oxide synthase (iNOS) mRNA expression and nitrite production were analyzed as a possible cytoprotective mechanism.

\section{Methods}

\section{Cell culture}

This study was approved by the Local Ethical Committee for Experimental Research at Dokuz Eylul University. Rat oligodendrocyte cultures were prepared from brains of newborn (1 to 2-day-old) Wistar rats as previously described (Genc et al. 2003). The cells were plated in $25-\mathrm{cm}^{2}$ poly-D-lysine (PDL)-coated flasks for the reverse transcriptase-polymerase chain reaction (RT-PCR), 96-well PDL-coated plates for cytotoxicity and cell viability assays, and nitrite measurement and PDL-coated glass coverslips in $35 \mathrm{~mm}$ Petri dishes for immunocytochemistry at a density of $5 \times 10^{4}$ cells $/ \mathrm{cm}^{2}$. Cells were grown in a medium containing Dulbecco's Minimum Essential Medium / Ham's F12 (DMEM/F12), $0.5 \%$ fetal bovine serum (FBS), and insulin-transferrinselenite (Roche) for another seven days. The cells plated onto PDL-coated glass coverslips were used for galactocerebroside $\mathrm{C}$ (GalC) immunocytochemistry as previously described (Genc et al. 2003). In these cultures more than $98 \%$ of cells were GalC stained oligodendrocytes (not shown). For experiments, cells were incubated with Epo for $24 \mathrm{~h}$ before the addition of toxic agents. Then, $1 \mu \mathrm{g} / \mathrm{ml}$ LPS (derived from Escherichia coli O26:B6; Sigma) and $100 \mathrm{U} / \mathrm{ml}$ recombinant rat IFN $\gamma(\mathrm{GIBCO})$ at various concentrations were added to cultures and incubated for $72 \mathrm{~h}$.

\section{$R T-P C R$ analysis}

For RT-PCR analysis of EpoR mRNA, cells were treated for $24 \mathrm{~h}$ with $1 \mu \mathrm{g} / \mathrm{ml}$ LPS and $100 \mathrm{U} / \mathrm{ml}$ IFN $\gamma$. After incubation, cells were rinsed with PBS and total RNA was isolated using Nucleospin RNA isolation kit (Macherey Nagel). RNA concentration was quantified spectrophotometrically. Isolated RNA was treated with DNase to digest any contaminant genomic DNA. RT-PCR amplification was carried out with $5 \mu \mathrm{g}$ RNA using primers for rat EpoR (sense 5'-CTATGGCTGTTG CAACGCGA-3'; antisense 5'-CCGAGGGCACAG GAGCTTAG-3') (Morishita et al. 1997), iNOS (sense 5'-CCACAATAGTACAATACTACTTGG-3'; antisense 5'-ACG AGGTGTTCAGCGTGCTCCACG-3') (Genc et al. 2003). Glyceraldehyde 3 phosphate dehydrogenase (GADPH) gene was used as an internal standard (sense 5'-ACCACAGTCCATGCCATCAC-3'; antisense 5'TCCACCACCCTGTTGCTGTA-3'). PCR reactions were carried out in a thermal cycler (Perkin Elmer Cetus). The steps of amplification were $95^{\circ} \mathrm{C}$ for $3 \mathrm{~min}, 95^{\circ} \mathrm{C}$ for $30 \mathrm{~s}, 55^{\circ} \mathrm{C} 30 \mathrm{~s}, 72{ }^{\circ} \mathrm{C} 1 \mathrm{~min}, 72{ }^{\circ} \mathrm{C} 5 \mathrm{~min}$ during 35 cycles for EpoR, 32 cycles for iNOS and 28 cycles for GAPDH. PCR products were resolved on $2 \%$ agarose gel. Optic density of each band was calculated using the Multianalyst software (1.1. version) and Densitometer GS700 (BioRad). The results were expressed by density ratios to GAPDH.

\section{Cytotoxicity assay}

Cytotoxicity was quantified by spectrophotometrically measuring release of lactate dehydrogenase (LDH) from cells into medium utilizing a commercially available kit (Cytotoxicity Detection Kit; Roche). To determine the percentage of cytotoxicity, the average absorbance values of the triplicates was calculated and the absorbance value obtained in the background control (media alone) was subtracted from each of these. The resulting values were substituted in the following equation: cytotoxicity (\%) $=$ (experimental value spontaneous release)/(maximum release - spontaneous release) $X 100$, where 'spontaneous release' means the LDH activity released from untreated normal cells. The maximum amount of releasable LDH enzyme activity was determined by lysing the cells with Triton X-100 (final concentration $1 \%$ Triton X-100). $50 \mu$ supernatant was removed from each well and transferred into an optically clear 96-well flat bottom microtiter plate. To 
determine LDH activity in these supernatants, a $50 \mu \mathrm{l}$ reaction mixture was prepared according to the manufacturer's instructions and added to each well. The absorbance of the samples was measured at $490 \mathrm{~nm}$ using an ELISA plate reader. The reference wavelength was $620 \mathrm{~nm}$.

\section{Nitrite measurement}

The activity of iNOS was evaluated by determination of nitrite levels in the supernatants as previously described (Genc et al. 2003). Nitrite is a stable product of $\mathrm{NO}$ and generated by the rapid oxidation of NO. Aliquots of $100 \mu \mathrm{l}$ culture supernatants were mixed with equal volumes of Griess reagent $(0.1 \%$ naphthylethylenediamine dihydrochloride, $1 \%$ sulphanilamide and $2.5 \%$ phosphoric acid) mixture in a 96-well microtitre plate (Maxisorb Immunoplate, NUNC). After 10 min of incubation at room temperature, the absorbance at a wavelength of $540 \mathrm{~nm}$ was measured in a microplate reader (Model 230S; Organon Technica). A range of twofold dilutions of sodium nitrite $(0-128 \mu \mathrm{M})$ in PBS were run in each assay to generate a standard curve.

\section{Statistical analysis}

Results are presented as mean \pm S.E.M. of three different separate experiments performed with separate cell cultures. Each condition was triplicated in each experiment. Multiple group comparisons of the differences in quantitative measurements were made by ANOVA and followed by $t$ test for statistical analysis. $\mathrm{P}<0.05$ was considered to be significant.

\section{Results}

RT-PCR analysis revealed that differentiated rat oligodendroglial cells express baseline EpoR mRNA (Fig. 1). PC12 cells were used as positive controls for EpoR mRNA expression. Inflammatory stimuli did not significantly change EpoR mRNA expression in rat oligodendrocytes as revealed by semiquantitative evaluation, densitometric ratios being $1.01 \pm 0.12$ in baseline condition and $1.30 \pm 0.09$ in LPS plus IFN $\gamma$ induced condition $(\mathrm{p}>0.05)$.

The cytotoxicity assay confirmed that the proinflammatory cytokine IFN $\gamma$ and LPS are toxic for oligodendrocytes in primary cell culture (Fig. 2). Erythropoietin demonstrated significant protection at all doses in oligodendrocyte cultures subjected to LPS + IFN $\gamma$-induced toxicity (Fig. 2). The magnitude of protection by Epo appears to be dose-dependent. Heatinactivated Epo did not show any effect on cell survival (data not shown).

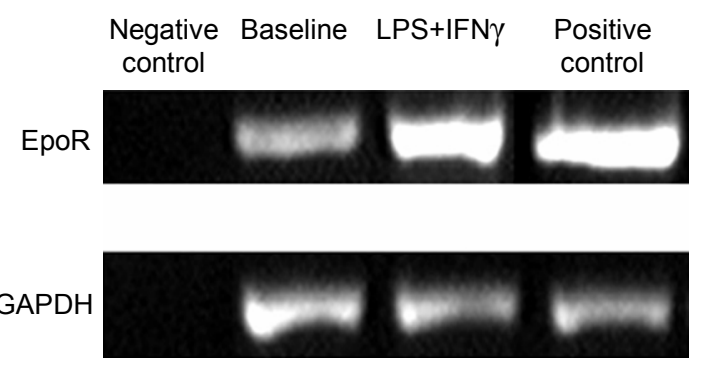

Fig. 1. Qualitative evaluation of EpoR mRNA expression in rat oligodendrocyte cultures. Cells were exposed to $100 \mathrm{U} / \mathrm{ml}$ rat IFN $\gamma$ plus $1 \mu \mathrm{g} / \mathrm{ml}$ LPS for $24 \mathrm{~h}$ and total RNA was extracted, and subjected to RT-PCR. Concomitantly, analysis of GAPDH mRNA was carried out. The agarose gels were photographed and scanned. Rat oligodendrocytes express EpoR in baseline conditions. Rat PC12 pheochromocytoma cell line was used as positive control for EpoR mRNA expression. RT enzyme was not used in negative control samples.

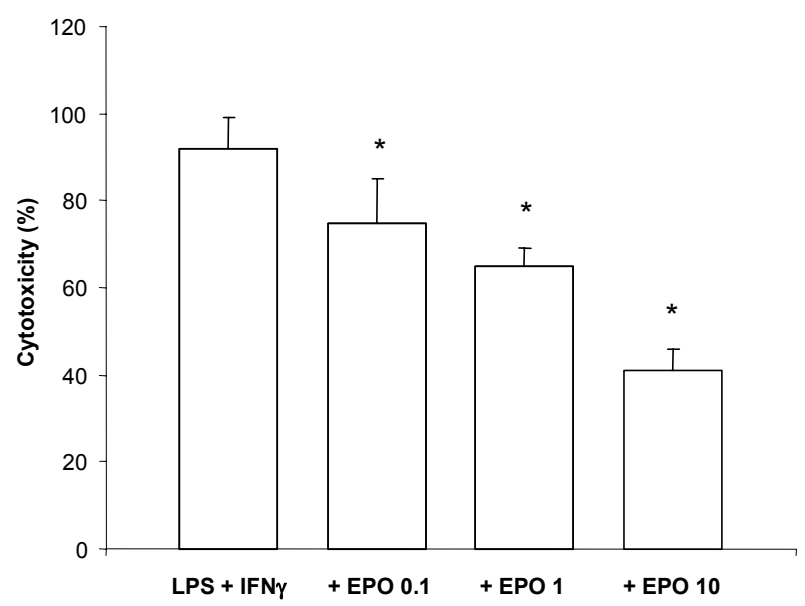

Fig. 2. Protective effect of Epo pretreatment on rat oligodendrocytes against cytotoxicity induced by LPS plus IFN $\gamma$. The results of the LDH assay reveal that Epo added to the cultures at various concentrations significantly decreases cytotoxicity induced by $1 \mu \mathrm{g} / \mathrm{ml}$ LPS and $100 \mathrm{U} / \mathrm{ml}$ IFN $\gamma$ exposure for $72 \mathrm{~h}(* \mathrm{p}<0.05)$. The results are means \pm SEM of triplicate conditions obtained from three independent experiments.

When iNOS mRNA expression was evaluated by RT-PCR, iNOS mRNA expression was not found under control conditions, but inflammatory stimuli apparently induced iNOS mRNA expression (Fig. 3A). Erythropoietin pretreatment $(1.0 \mathrm{U} / \mathrm{ml})$ resulted in a significant decrease in increased iNOS mRNA expression. Densitometric ratios were $2.03 \pm 0.10$ and $0.86 \pm 0.04$ for with Epo and without Epo conditions, respectively $(p<0.05)$. The activity of iNOS was also 
evaluated by determination of nitrite levels in the supernatants. As shown in Figure 3B, $72 \mathrm{~h}$ exposure of rat oligodendroglial cells to $1 \mu \mathrm{g} / \mathrm{ml} \mathrm{LPS}$ and $100 \mathrm{U} / \mathrm{ml}$ IFN $\gamma$ significantly increased nitrite production. Pretreatment of cultures with Epo $(1.0 \mathrm{U} / \mathrm{ml}) 24 \mathrm{~h}$ before LPS and IFN $\gamma$ exposure produced significant reduction in induced-nitrite levels.

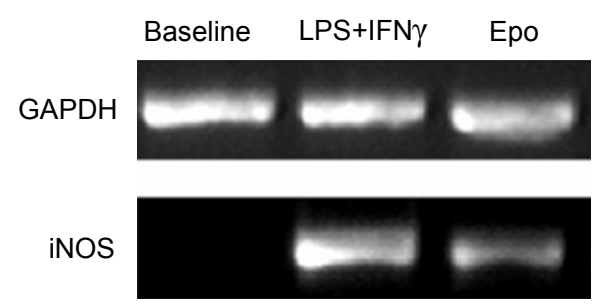

Fig. 3A. The effect of Epo pretreatment $(1.0 \mathrm{U} / \mathrm{ml})$ on iNOS mRNA expression upon $1 \mu \mathrm{g} / \mathrm{ml}$ LPS and $100 \mathrm{U} / \mathrm{ml}$ IFN $\gamma$ exposure in rat differentiated oligodendrocyte cultures. Cells were exposed to Epo for $24 \mathrm{~h}$ and then, LPS and IFN $\gamma$ were added to cultures. After $24 \mathrm{~h}$ incubation, cells were lysed and total RNA was extracted, and subjected to RT-PCR. Concomitantly, analysis of GAPDH mRNA was carried out. The agarose gels were photographed and scanned. Epo pretreatment decreases iNOS mRNA expression induced by inflammatory stimuli.

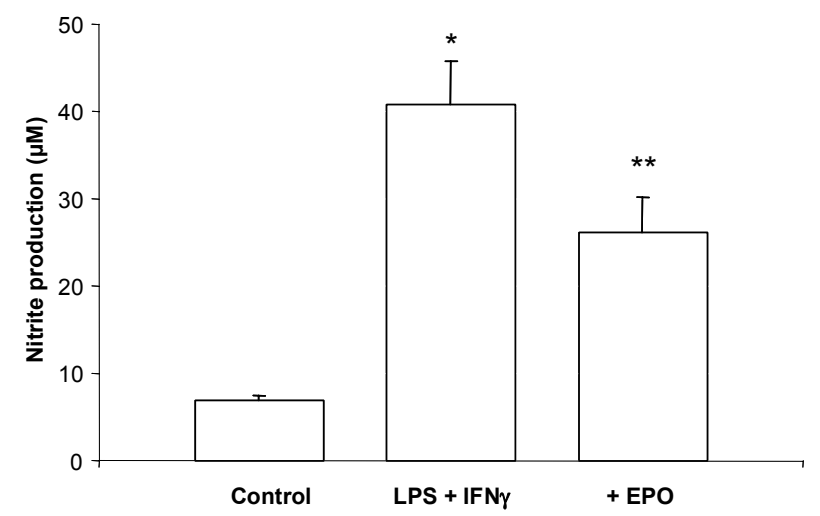

Fig. 3B. The effect of Epo pretreatment $(1.0 \mathrm{U} / \mathrm{ml})$ on endogenous nitrite production in differentiated rat oligodendrocytes. Cells were exposed to Epo for $24 \mathrm{~h}$ and then, $1 \mu \mathrm{g} / \mathrm{ml} \mathrm{LPS}$ and $100 \mathrm{U} / \mathrm{ml}$ IFN $\gamma$ were added to cultures. After another $72 \mathrm{~h}$ incubation, production of nitrite was determined in $100 \mu \mathrm{l}$ aliquots of culture supernatant. The values represent the mean \pm SEM of three independent experiments performed in triplicate. $72 \mathrm{~h}$ exposure of rat oligodendroglial cells to $1 \mu \mathrm{g} / \mathrm{ml}$ LPS and $100 \mathrm{U} / \mathrm{ml}$ IFN $\gamma$ significantly induced nitrite production $(* \mathrm{p}<0.05)$. Epo pretreatment significantly decreases LPS plus IFN $\gamma$-induced nitrite production ( $* * p<0.05$ ).

\section{Discussion}

In the present study, the protective effect of erythropoietin on oligodendrocyte viability has been evaluated in cells at only a single stage of oligodendrocyte lineage, i.e. in differentiated GalCpositive cells. Additional compromising factors such as cytotoxicity due to activation of contaminant microglial cells or protection due to contaminant astroglial cells were excluded by the high purity of cultures. This is important because of the differential sensitivity of oligodendroglial cells from different developmental stages to toxic factors and injury (Baerwald and Popko 1998, Benn et al. 2001). The response of oligodendrocytes from other developmental stages (progenitors or immature oligodendrocytes) to inflammatory stimuli and the effect of Epo treatment was not our focus in this study and further studies are needed to clarify this issue.

A recent study has shown EpoR on rat oligodendrocytes (Sugawa et al. 2002) and this finding was confirmed in the present study. Rodent oligodendrocytes are also known to express IFN $\gamma$ receptor (Torres et al. 1995). The cytotoxic effect of proinflammatory cytokines and LPS in oligodendrocyte are well documented by in vitro studies (Baerwald and Popko 1998, Molina-Holgado et al. 2001). The presence of proinflammatory cytokines in multiple sclerosis (MS) lesions and the correlation between the levels of these and disease activity have been reported (Cannela and Raine 1995). The present study is the first in vitro demonstration of the protective effect of Epo on oligodendrocyte injury induced by IFN $\gamma$ and LPS. Epo treatment following inflammatory injury did not show protection in rat oligodendrocytes (not shown). Although pretreatment with Epo might not fit to the clinical setting, Epo treatment may provide some benefit on ongoing oligodendroglial injury. Epo has ameliorating effects on the clinical status in the rat MS model (Agnello et al. 2002). In addition, anti-inflammatory effects of Epo have been determined in head injury model (Brines et al. 2000). A recent study using a rat spinal trauma model has shown the ameliorating effect of systemic Epo treatment on delayed white matter injury and apoptotic cell death (Gorio et al. 2002).

The present results suggest a mechanism of Epo protection, i.e. decrease of iNOS derived NO production induced by inflammatory stimuli. Recent evidence suggests that oligodendrocytes, apart from being a target, may be a source of cytokines and NO in inflammatory conditions (Merrill et al. 1997, Molina-Holgado et al. 2001). Among cytotoxic effector molecules evoked by the proinflammatory stimuli, increasing evidence supports a role of $\mathrm{NO}$ in MS and oligodendrocyte damage 
(Bagasra et al. 1995, Mitrovic et al. 1995, Smith and Lassmann 2002). For this reason, we focused here on clarifying whether Epo has any effect on oligodendroglial inducible NO production and confirmed the suppressive effect of Epo on endogenous inducible NO production in rat oligodendrocytes. Epo has been shown to inhibit brain NO production in a global cerebral ischemia model (Calapai et al. 2000). However, no inhibiting effect of Epo on cultured microglial baseline NO production has been observed (Vairano et al. 2002). The effect of Epo on inducible NO production has not been evaluated in that study. The results of another recent study suggest that Epo protects neurons from NO-related neuronal apoptosis, but does not affect NO levels (Digicaylioglu and Lipton 2001). The effect of Epo on iNOS and inducible NO production may be cell type-specific.
The results of the present study suggest that Epo, in addition to its neuroprotective effect, might be a useful agent to protect oligodendrocytes in many clinical situations such as MS, characterized by primary oligodendrocyte injury, or trauma and hypoxic and ischemic injury of the CNS, which also affect white matter and oligodendrocyte survival.

\section{Acknowledgements}

This work was supported by Dokuz Eylul University Research Foundation and The Scientific and Technical Research Council of Turkey. Authors thank Dr. Alexis Brice (INSERM U289 in Paris) for the PC12 cell line. We are indebted to Dr. Tolga F. Koroglu for reviewing the linguistic aspects of the manuscript.

\section{References}

AGNELLO D, BIGINI P, VILLA P, MENINI T, CERAMI A, BRINES ML, GHEZZI P: Erythropoietin exerts antiinflammatory effect on the CNS in a model of experimental autoimmune encephalomyelitis. Brain Res 952: 128-134, 2002.

BAERWALD KD, POPKO B: Developing and mature oligodendrocytes respond differently to the immune cytokine interferon-gamma. J Neurosci Res 52: 230-239, 1998.

BAGASRA O, MICHAELS FH, ZHANG YM, BOBROSKI L, SPITSIN SV, Fu ZF, TAWADROS R, KOPROWSKI $\mathrm{H}$ : Activation of the inducible form of nitric oxide synthase in the brains of patients with multiple sclerosis. Proc Natl Acad Sci USA 92: 12041-12045, 1995.

BENN T, HALFPENNY C, SCOLDING N: Glial cells as targets for cytotoxic immune mediators. Glia 36: 200-211, 2001.

BRINES ML, GHEZZI P, KEENAN S, AGNELLO D, DE LANEROLLE NC, CERAMI C, ITRI LM, CERAMI A: Erythropoietin crosses the blood-brain barrier to protect against experimental brain injury. Proc Natl Acad Sci USA 97: 10526-10531, 2000.

CALAPAI G, MARCIANO MC, CORICA F, ALLEGRA A, PARISI A, FRISINA N, CAPUTI AP, BUEMI M: Erythropoietin protects against brain ischemic injury by inhibition of nitric oxide formation. Eur J Pharmacol 401: 349-356, 2000.

CANNELA BC, RAINE CS: The adhesion molecules and cytokine profile of multiple sclerosis lesions. Ann Neurol 37: 424-435, 1995.

DIGICAYLIOGLU M, LIPTON SA: Erythropoietin-mediated neuroprotection involves cross-talk between Jak2 and NF- $\kappa$ B signalling cascades. Nature 412: 641-647, 2001.

GENC S, GENC K, KUMRAL A, BASKIN H, OZKAN H: Bilirubin is cytotoxic to rat oligodendrocytes in vitro. Brain Res 985: 135-141, 2003.

GENC S, KOROGLU TF, GENC K: Erythropoietin and the nervous system. Brain Res 1000: 19-31, 2004.

GORIO A, GOKMEN N, ERBAYRAKTAR S, YILMAZ O, MADASCHI L, CICHETTI C, DI GIULIO AM, VARDAR E, CERAMI A, BRINES M: Recombinant human erythropoietin counteracts secondary injury and markedly enhances neurological recovery from experimental spinal cord trauma. Proc Natl Acad Sci USA 99: 9450-9455, 2002.

MAIESE K, LI F, CHONG ZZ: Erythropoietin in the brain: can the promise to protect be fulfilled? Trends Pharmacol Sci 25: 577-83, 2004. 
MERRIL JE, MURPHY SP, MITROVIC B, MACKENZIE-GRAHAM A, DOPP JC, DING M, GRISCAVAGE J, IGNARRO LJ, LOWENSTEIN JC: Inducible nitric oxide synthase and nitric oxide production by oligodendrocytes. J Neurosci Res 48: 372-384, 1997.

MITROVIC B, IGNARRO LJ, MONTESTRUQUE S, SMOLL A, MERRIL JE: Nitric oxide as a potential pathological mechanism in demyelination: its differential effects on primary glial cells in vitro. $J$ Neurosci 61: 575-585, 1995.

MOLINA-HOLGADO E, VELA JM, AREVALO-MARTIN A, GUAZA C: LPS/IFN $\gamma$ cytotoxicity in oligodendroglial cells: role of nitric oxide and protection by the anti-inflammatory cytokine IL-10. Eur J Neurosci 13: 493-502, 2001.

MORISHITA E, MASUDA S, NAGAO M, YASUDA Y, SASAKI R: Erythropoietin receptor is expressed in rat hippocampal and cerebral cortical neurons, and erythropoietin prevents in vitro glutamate-induced neuronal death. Neuroscience 76: 105-116, 1997.

SMITH KJ, LASSMANN H: The role of nitric oxide in multiple sclerosis. Lancet Neurol 4: 232-241, 2002.

SUGAWA M, SAKURAI Y, ISHIKAWA-IEDA, SUZUKI H, ASOU H: Effects of erythropoietin on glial cell development; oligodendrocyte maturation and astrocyte proliferation. Neurosci Res 44: 391-403, 2002.

TORRES C, ARANGUEZ I, RUBIO N: Expression of interferon- $\gamma$ receptors on murine oligodendrocytes and its regulation by cytokines and mitogens. Immunology 86: 250-255, 1995.

VAIRANO M, DELlo RUSSO C, POZZOLI G, BATTAGLIA A, SCAMBIA G, TRINGALI G, ALOE-SPIRITI MA, PREZIOSI P, NAVARA P: Erythropoietin exerts anti-apoptotic effects on rat microglial cells in vitro. Eur $J$ Neurosci 16: 584-592, 2002.

\section{Reprint requests}

Kursad Genc, Learning Resources Center Research Laboratory, School of Medicine, Dokuz Eylul University, Inciralti, 35340, Izmir, Turkey. E-mail: kkursadgenc@hotmail.com 